\title{
Improving the Performance of MPPT on DC Grid PV Systems by Modified Incremental Conductance Algorithm
}

\author{
Mehmet Ali Özçelik and Ahmet Serdar Yılmaz
}

\begin{abstract}
The performance of photovoltaic (PV) system is affected by temperature, solar insolation, solar panel configuration and shading. In order to succeed maximum efficiency, PV arrays should operate at their maximum power point (MPP). Hence, the MPP tracking (MPPT) unit is implemented among the PV energy conversion system to obtain maximum power. In this study, incremental conductance (IC) algorithm, the most commonly used algorithm in MPPT systems for expectation-maximization, was analysed and an approach towards eliminating ripple problems, improving speed to obtain more power value, were maintained and duty cycle (Dk) value was obtained from IC algorithm under changing PV panel radiation conditions. In the end, it was evaluated alongside with MATLAB simulation results.
\end{abstract}

Index Terms-Photovoltaic (PV) cell, incremental conductance, maximum power point tracking (MPPT), boost DC/DC converter.

\section{INTRODUCTION}

Recently, studies about PVs have focused on minimizing the costs and maximizing the conversion efficiency. In MPP, PV arrays generate the electric energy at maximum efficiency and minimum losses. PV cells have variable current and voltage characteristics and maximum power point depends on solar irradiations and environment temperature. Because of that a maximum power tracking control should be made rapidly in varied temperature and solar insolation conditions. Maximum power point trackers (MPPT) are improved to catch maximum power level in different atmospherically conditions [1]. So as to maximize the conversion efficiency and captured energy from solar arrays, the PV system should be operated at its maximum power point [2].

Although PV systems continue to occupy an important position in electrical power technology, they have disadvantages such as high cost and low conversion efficiency.

This is largely because of the fact that output voltage and current values vary in a nonlinear way depending on solar radiation intensity, operating temperature and load current. In this context, a converter based on power electronics was needed so as to track variable voltage and current among panel and load. In Fig. 1, I-V and P-V characteristics of a solar module in the simulations are showed.

Manuscript received November 25, 2016; revised February 15, 2016.

Mehmet Ali Özçelik is with Gaziantep University, Vocational School of Technical Sciences, Electric and Energy Department, Gaziantep, Turkey (e-mail: ozcelik@gantep.edu.tr).

Ahmet Serdar Yllmaz is with Kahramanmaras Sutcu Imam University, Engineering Faculty, Electrical-Electronics Eng. Department, Kahramanmaras, Turkey (e-mail: asyilmaz@ksu.edu.tr).

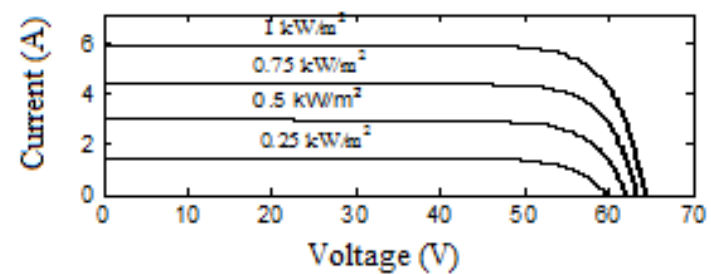

(a)

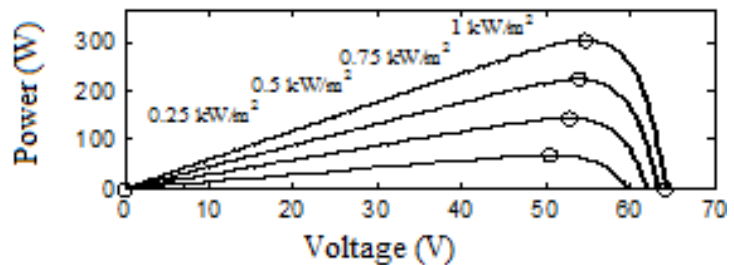

(b)

Fig. 1. Characteristics of solar module in the simulations (a) I-V Curve (b) P-V Curve.

This is largely because of the fact that output voltage and current values vary in a nonlinear way depending on solar radiation intensity, operating temperature and load current. In this context, a converter based on power electronics was needed so as to track variable voltage and current among panel and load. It is also important to track this intermediary block where DC/DC converters are used. The triggering frequency and range of switching Mosfet/IGBT in the converter have a significant part to obtain maximum power value.

The suitable converter type is a significant case for MPPT design. Buck, boost and buck - boost types are mostly preferred. Boost converters require more inductance than the buck converter type, to achieve the same ripple of inductor current. In these converter types, the effective current through inductor is much less than that of buck converters. But, Buck converters require larger and more expensive input capacitors than Boost type to even the discontinuous input current from solar array. Polarity of output voltage Buck/Boost type varies. Hence, several converter types have been tested, suggested in literature. In addition to well-known buck, boost and buck-boost types, second generation converters such as SEPIC [3], [4] and CUK [5], [6] are used in this field as well as isolated flyback and forward [7] type converters used when higher voltage conversion is required.

Furthermore, previous studies suggested various controlling methods for MPPT design. Fuzzy logic [8] digital signal processing (DSP) controllers [9], field programmable gate array (FGPA) controllers [10], [11], parallel processing topology [12] are some of the important methods and controllers. In conventional PV, energy conversion systems consist of serial connected solar panel, DC/DC converter and battery (or DC load) as shown in Fig. 2. 


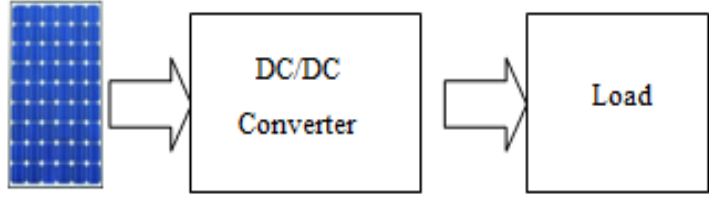

PV Arrays

Fig. 2. Conventional PV energy conversion system.

In the literature, both converter design and MPPT algorithms have been studied and presented so far. To reach maximum power point faster, several algorithms such as Perturbation and Observation (P\&O) [13], [14], incremental conductance [15], look-up table [16], [17], current control loop [18] were proposed and applied.

This study focuses on an optimization of incremental conductance algorithm. The chief advantage of this method is that it doesn't necessitate high "complexity implementation" and that it requires less calculation parameters. The disadvantage being that it generates ripple when it reaches the maximum power point. Conventional IC algorithm is used with constant iteration step size, it decision-making speed increases in proportion to step size of error. But, higher error step size reduces the efficiency of MPPT. This difficulty causes the power losses and difficult the control actions. Therefore, some calculation procedures of conventional IC algorithm were modified.

\section{PV SYSTEM}

\section{A. PV Cell Model}

A photovoltaic cell is basically a $\mathrm{PN}$ semiconductor junction diode that converts energy. As the sun light drops on PV cells, photo-power acts like a forward diode on a large surface. The current expression emerging as a result of the sunlight hitting on the cell is given in 1 .

$$
I=I_{P H}-I_{S} \cdot\left\{\exp \left[\frac{q}{A \cdot k \cdot T}\left(V+I \cdot R_{L}\right)\right]-1\right\}-\frac{\left(V+I \cdot R_{S}\right)}{R_{S H}}(1)
$$

In this expression, photo-current, saturation current, load resistance, series equivalent circuit resistance, parallel equivalent circuit resistance, terminal voltage and load current are denoted by $I_{P H}, I_{S}, R_{L}, R_{S}, R_{S H}, V$ and $I$, respectively. The equivalent circuit diagram for a solar cell is shown in Fig. $3[19]$.

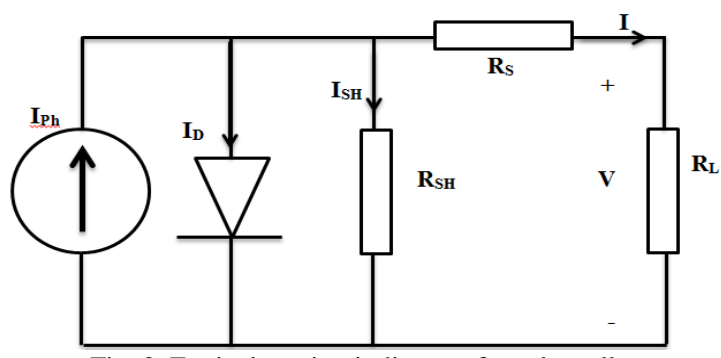

Fig. 3. Equivalent circuit diagram for solar cells.

Solar cells have a current source that are connected with a parallel diode and resistance, to which is connected a serial resistance. PV panels are built through series or parallel connection of these solar cells. The relation between the voltage of solar battery cells and current switched on the load exposes I-V and P-V characteristics of the cell. These two characteristics give important clues as to which conditions are required in order for the power obtained from the panel to reach its maximum level.

Obtaining maximum power and reaching highest efficiency level in these panels is an importance research topic. Solar panels act like a current source while, from a certain point onward, they act like a voltage source. Current value that can be obtained from a solar panel is fixed even in case of a short circuit. This value is given along with the label of the panel. It is necessary to obtain maximum power from $\mathrm{PV}$ panels in any insolation condition. Maximum power point for PV systems varies depending on atmospheric conditions, which are ambient temperature and insolation amount. In general, PV solar panels reach their maximum power point at around $25^{\circ} \mathrm{C}$. Two parallel connecting photovoltaic arrays are used in this study. PV panel has electrical parameters are given in Table I.

TABLE I: ELECTRICAL CHARACTERISTICS OF PV PANEL

\begin{tabular}{|l|c|}
\hline Module specifications under STC & Parameters \\
\hline Open-circuit voltage $\left(V_{o c}\right)$ & $64.2 \mathrm{~V}$ \\
\hline Short-circuit current $\left(I_{s c}\right)$ & $5.96 \mathrm{~A}$ \\
\hline Voltage at $P_{\max }\left(V_{m p}\right)$ & $54.7 \mathrm{~V}$ \\
\hline Current at $P_{\max }(I m p)$ & $5.58 \mathrm{~A}$ \\
\hline Number of series-connected modules per string & 5 \\
\hline Number of parallel string & 66 \\
\hline
\end{tabular}

\section{B. Boost (Step Up) Type DC/DC Converter}

Boost converter, as its name implies, is a structure that boosts the voltage. Its simplified circuit diagram is shown in Fig. 4. In PV systems, input voltage defined as $V_{S}$ is the voltage in the panel while output voltage, defined as $V_{O}$, is the battery or load voltage.

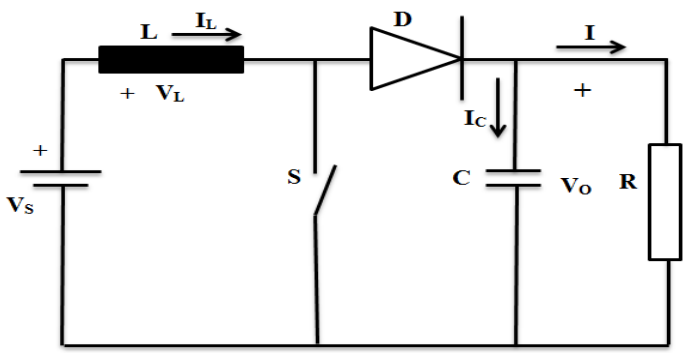

Fig. 4. Circuit diagram for boost DC/DC converter.

Mosfet or IGBT is used as switching element. $D$ (duty cycle), which describes relative conduction time, equals to switching element conduction time $\left(t_{\mathrm{on}}\right)$ divided by signal period which is the total conduction and cut-off time $\left(T=T_{\text {on }}\right.$ $\left.+T_{\text {off }}\right)$.

$$
D=\frac{t_{\text {on }}}{t_{\text {on }}+t_{\text {off }}}=\frac{t_{\text {on }}}{T}
$$

The conversion is performed in this converter as follows:

While switching element $(S)$ turn on, PV structure injects additional energy to inductance through driving current over inductance $(L)$. Then, switching element is cut off and reverse 
current force in the inductance charges the capacity element over the diode. The relationship between output voltage and input voltage is as follows:

$$
\begin{gathered}
V_{S}=\frac{1}{1-D} V_{O} \\
\frac{I}{I_{p v}}=1-D
\end{gathered}
$$

Boost structures are often preferred in stand-alone systems and when panel voltage is lower than battery voltage.

\section{ESSENTIALS OF INCREMENTAL CONDUCTANCE ALGORITHM}

This algorithm is also called hill climbing. The incremental conductance algorithm is derived from the PV array power together respect to voltage and setting the equal to zero. The algorithm is given by the following Eq. (5).

$$
\frac{d P}{d V}=\frac{d(V I)}{d V}=I+V \frac{d I}{d V}=0
$$

By accounting for the depended of the PV current on the voltage, it is possible to express such a condition as follows Eq. (6) [20].

$$
I+V \frac{d I}{d V}=0
$$

So that the validity of condition (5) is equivalent to follows Eq. (7).

$$
\frac{I}{V}=-\frac{d I}{d V}
$$

Which means that left-hand side of Eq. (7) represents the opposite of the PV array's instantaneous conductance, as the right-hand side represents its incremental conductance.

As a consequence, the method requires the application of a repeated perturbation of the voltage value, until the next condition occurs Eq. (8) [21].

$$
\frac{I_{k}}{V_{k}}=-\frac{I_{k}-I_{k-1}}{V_{k}-V_{k-1}}
$$

where the subscript $k$ and $k-1$ refer to two consecutive samples of the PV voltage and current values. The conventional algorithm (IC) is shown Fig. (5) [22].

At the maximum power point, the equations occurs in the following Eq. (9a, 9b, 9c).

$$
\begin{gathered}
\frac{d I}{d V}=-\frac{I}{V} ;\left(\frac{d P}{d V}=0\right), \text { at MPP } \\
\frac{d I}{d V}>-\frac{I}{V} ;\left(\frac{d P}{d V}>0\right), \text { left of MPP }
\end{gathered}
$$

$$
\frac{d I}{d V}<-\frac{I}{V} ;\left(\frac{d P}{d V}<0\right), \text { right of MPP }
$$

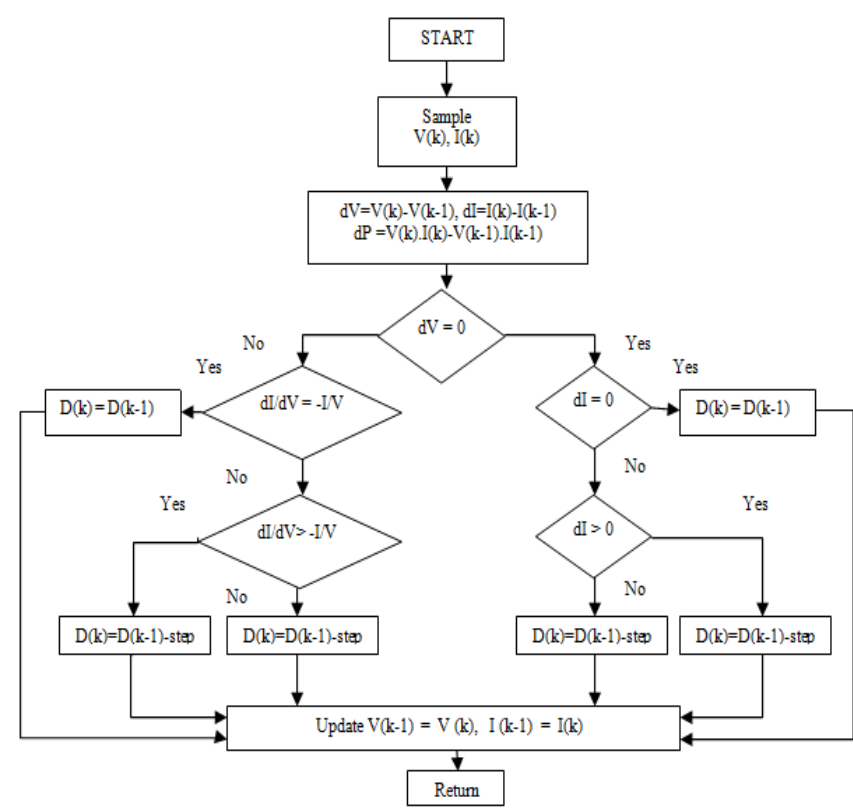

Fig. 5. Flowchart of the IC algorithm.

Equation (9a) is repeat of equation (7) for accordance, equation $(9 b)$ and $(9 c)$ are used to determine the direction where a perturbation must occur to move the operating point toward the MPP, and the perturbation is repeated until equation (9a) is pleased. When the maximum power point is reached, the MPPT go on to work at this point up to a change in current measured. This change in current will correlate to a change in irradiance on the array. The increment step decide how fast the MPP is tracked. Rapid tracking can be succeed with large increments however, the system may not work completely at the MPP and ripple around in place of it; because of that there is a trade-off.

\section{Proposed InCREMENTAL CONDUCTANCE Algorithm}

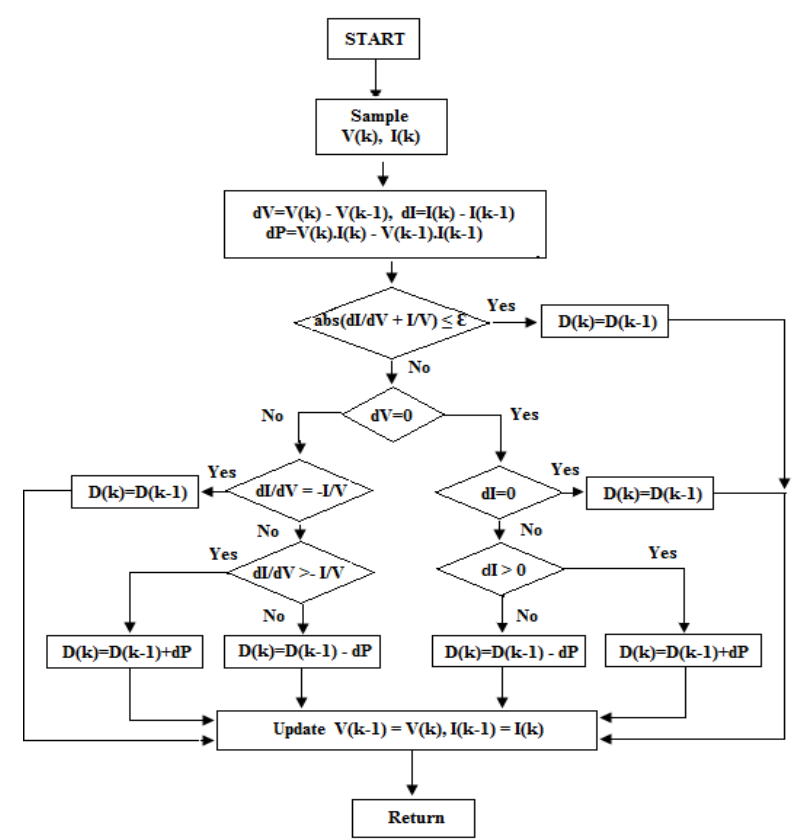

Fig. 6. Flowchart for proposed IC algorithm. 
In the proposed algorithm, instead of fixed step coefficient used to increase or decrease duty cycle, $\Delta P$, denoting amount of power change, is used in order to approach maximum power point in proportion to an increase or decrease. In other words, a parallel coefficient was provided for power change to faster identify maximum power point. In case of no power change, $\Delta P=0$, no iteration was performed and oscillation was minimized. In addition, At MPP, $d I / d V+I / V=0$ and no iteration is performed. Epsilon $(\varepsilon)$ is a number close to zero but it is not zero. This $\varepsilon$ value can generate ripple under the variable solar irradiation [23]. The ripple produces power loss So, if absolute value of $d I / d V+I / V$ is smaller or equal than $\varepsilon$, the step of duty cycle will be reset $(\triangle P=0)$ which means that $D(k)=D(k-1)$ and ripple around maximum power point is eliminated. The proposed algorithm is shown in Fig. 6.

The algorithm shown in Fig. 6 was designed in order to prevent ripple emerging during attempts to identify maximum power point of the incremental conductance algorithm and to faster identify this point following significant power changes. In this approach, $\Delta P=P_{k}-P_{k-1}$ denotes power change. When panel and DC converter duty cycle $(D k)$ is increased or decreased in accordance with this power change, it is found out in the simulation results that ripple is reduced and $D k$ at maximum power point is identified sooner. In case of no power change, $\Delta P=0$ or abs $(d I / d V+I / V) \leq \mathcal{E}$ no iteration is performed. In this case, ripple around maximum power point under variable solar irradiation is eliminated and improving the algorithm.

When power change increases, iteration coefficient increases. Otherwise, iteration coefficient decreases. At left side of MPP, If $D k$ increases, power increase and if $D k$ decreases, power decreases too. Oppositely, at right side of MPP, when $D k$ increases, power will decrease and when $D k$ decreases, power will increase too. Therefore, when duty cycle is changed, if there is an increasing in power, changing on same way should be kept on (step which equal absolute value $\Delta P$ should be added). If there is a decreasing in power, changing should be continued on inverse way. ( $\Delta P$ should be subtracted). If $D k$ is $>D_{\max }$ or if $D k<D_{\min }$ then $D$ is to be equaled to $D(k-1)\left(D_{\max }\right.$ and $D_{\min }$ are duty cycle limits of the $\mathrm{DC} / \mathrm{DC}$ boost converter).

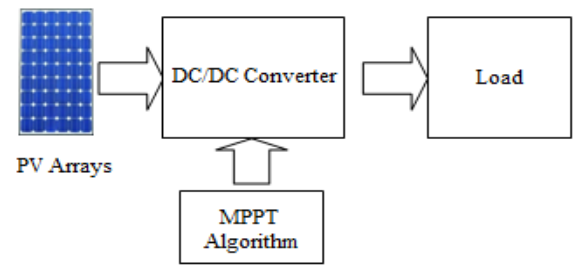

Fig. 7. Essential block of studied system with MPPT.

In Fig. (7), MPPT block structure where simulation is performed is shown. MPPT is a power tracking system that enables to obtain maximum power from PV panels. In MPPT block, DC/DC converter is controlled by IC algorithm through producing duty cycle. As a result of this, the maximum power level from PV panel is reached.

\section{COMPARISON OF CONVENTIONAL AND PROPOSED INCREMENTAL CONDUCTANCE ALGORITHM}

In simulations, two cases are applied to compare to both algorithms. In the first case, outputs of PV panels are considered when insolation decreases. In the second one, same parameters are also tested when insolation increases or decreases.

Case 1: Results obtained from the modelling in Matlab/Simulink are presented in this case. Solar irradiation is around $1000 \mathrm{~W} / \mathrm{m}^{2}$ at starting point. Irradiation is decreased to about $980 \mathrm{~W} / \mathrm{m}^{2}$ linearly until 0.5 th seconds.

In this case, a linear decrease was observed in the system which is exposed to a radiation rate of about $1000 \mathrm{~W} / \mathrm{m}^{2}$ for 0.5 seconds and the radiation decreased to nearly $980 \mathrm{~W} / \mathrm{m}^{2}$. In view of this change, which can be considered as fast, classical method and response of identical systems operated by modified method were compared. Power and current responses are compared in Fig. 8 and Fig. 9.
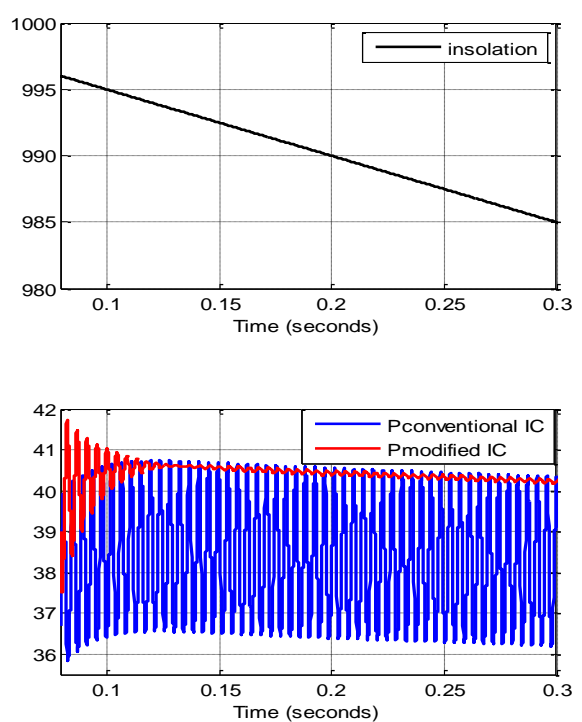

Fig. 8. Solar insolation, Output power of DC system for modified and conventional IC algorithms case 1 .

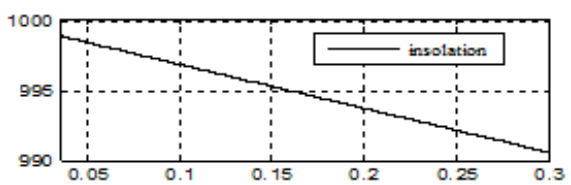

(a)

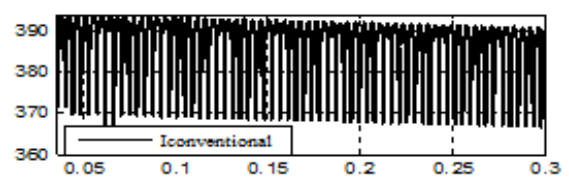

(b)

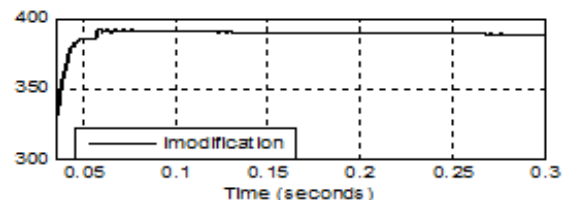

(c)

Fig. 9. (a) Solar insolation, (b) output of current DC system conventional (c) modified IC algorithm case 1 .

Case 2 Results obtained from the modelling in Matlab/Simulink are presented in this case. Solar irradiation is about $950 \mathrm{~W} / \mathrm{m}^{2}$ at starting point, it is increased to about $1250 \mathrm{~W} / \mathrm{m}^{2}$, it is decreased about $950 \mathrm{~W} / \mathrm{m}^{2}$ and it is increased nearly $1000 \mathrm{~W} / \mathrm{m}^{2}$ linearly until 3 th seconds. In view of this changes, which can be considered as fast, conventional 
algorithm and response of identical systems operated by modified method were compared similar to Case I. Power and current, responses are compared in Fig. 10 and Fig. 11.

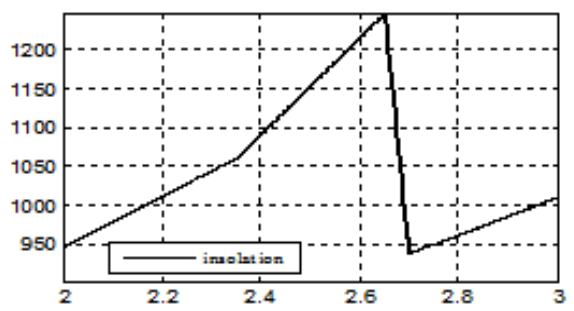

(a)

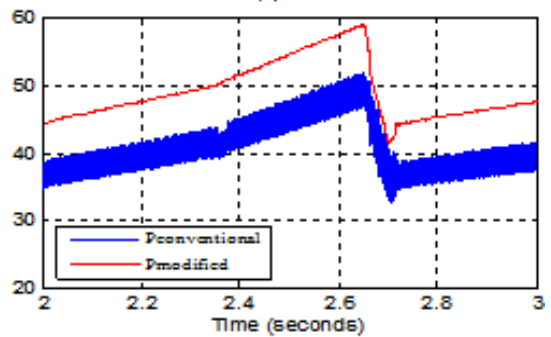

(b)

Fig. 10. (a) Variable solar insolation, (b) Output power of DC system for conventional and modified IC algorithm case 2.

TABLE II: OUTPUT POWERS UNDER VARIOUS SOLAR IRRADIANCE

\begin{tabular}{|c|c|c|c|c|}
\hline $\mathbf{W} / \mathbf{m}^{\mathbf{2}}$ & Second & $\begin{array}{c}\text { Pmodified } \\
(\mathbf{k W})\end{array}$ & $\begin{array}{c}\text { Pconventional } \\
(\mathbf{k W})\end{array}$ & $\boldsymbol{\Delta}$ \\
\hline 946 & 2.0 & 44 & 37 & 7 \\
\hline 1011 & 2.2 & 48 & 41 & 7 \\
\hline 1090 & 2.4 & 52 & 43 & 9 \\
\hline 1220 & 2.6 & 48 & 58 & 10 \\
\hline 962 & 2.8 & 45 & 37 & 7 \\
\hline 1010 & 3.0 & 47 & 40 & 7 \\
\hline
\end{tabular}

In Fig. 10, it is demonstrated that in highly changing solar irradiance conditions and in shorter time intervals, the modified algorithm produces a higher value of power and less oscillation under the changing conditions.

According to Table II $\Delta_{\text {mean }}=7.83 \mathrm{~kW}$ and when the differences between output powers are considered, the rate in the lowest irradiation case is $7 \mathrm{~kW}$ while in the highest case there is a difference of $10 \mathrm{~kW}$.
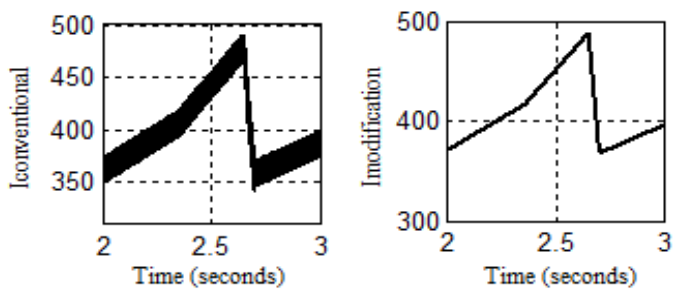

Fig. 11. Output current of DC system for conventional and modified IC algorithms case 2 .

It can be seen from the results of two cases, that modified IC algorithm reaches to less time maximum power point than conventional IC algorithm in this process. In addition, modified IC algorithm produces less ripple than conventional IC algorithm under rapidly changing solar insolation conditions.

However, in conventional IC algorithm, both ripples occur and maximum power point is attained slightly later. Particularly, as shown in Fig. 8 and Fig. 10 power ripples are to continue for a specific period of time. These ripples affect total efficiency of the system negatively, too. Losses may be encountered due to changing parameters as a result of ripples.

As these results suggest, the modified IC algorithm has a good advantage with regards to ripple and improving performance in the conventional IC algorithm. Ripple around MPP is great difficulty of the conventional IC algorithm and this proposed method arranges this problem and improving efficiency with under this conditions.

\section{CONCLUSIONS}

PV systems have a low efficiency in general. System efficiency involves many equipment and parameters in the system. Efficiency of a single solar cell may differ from that of the panels comprising of these cells. Problems during installation negatively affect panel efficiency. There are also other factors such as panel angle, obstruction from high buildings or cloudy weather conditions which cause total or partial shadowing and thus decrease total efficiency. In addition, software and hardware problems in MPPT decrease efficiency. Switching losses in converter circuit may have negative influence on total efficiency. Slow response rate of the algorithm and, as stated in this study, occurrence of ripples are also important problems under changing solar insolation conditions. These factors force us to improve the algorithm.

This study focuses on improving algorithm and eliminating ripple problems, and rapidly reaching more power value than conventional IC algorithm in PV systems. Especially, when variability increases as a result of factors such as partial shadowing and cloudy weather, these ripples badly affect the performance of the system. In order to increase the efficiency of system, it is suggested that the algorithm should be improved accordingly. It is also possible to suggest that changes in the algorithm will bring out no difficulties in terms of hardware, which makes it suitable for experimental purposes. An improved IC algorithm is used to modulate the duty cycle of the boost DC/DC converter, and thus, the tracking speed increased. It is concluded that the proposed algorithm shows better performance than conventional IC algorithm under changing conditions and it reduces the power losses.

\section{REFERENCES}

[1] G. A. M. Brito, L. Galotto, L. P. Sampaio, G. A. Melo, and C. A Canesin, "Evaluation of the main MPPT techniques for photovoltaic applications," IEEE Transactions on Industrial Electronics, vol. 60, no. 3, pp. 1156-1167, 2013.

[2] D. P. Hohm and M. E. Ropp, "Comparative study of maximum point tracking algorithms using an experimental, programmable, maximum Powerpoint tracking test bed," in Proc. 28th IEEE Photovoltaic Spec. Conf., 2000, pp. 1699-1702.

[3] M. Veerachary, "Power tracking for non-linear PV sources with coupled inductor SEPIC converter," IEEE Trans. Aerospaceand Electronic Systems, vol. 41, pp. 1019-1029, 2005.

[4] S. J. Chiang, S. Hsin-Jang, and C. Ming-Chieh, "Modeling and control of PV charger system with SEPIC converter," IEEE Trans. Industrial Electronics, vol. 56, pp. 4344-4353, 2009

[5] D. C. Raiwan and C. V. Nayar, "Analysis and design of a solar charge controller using Cuk converter," in Proc. Aust. Univ. Power Eng. Conf., 2007, pp. 1-6.

[6] A. Safari, "Simulation and hardware implementation of incremental conductance MPPT with direct control method using Cuk converter," 
IEEE Trans Industrial Electronics, vol. 58, no. 4, pp. 1154-1161, 2011.

[7] B. J. D. Vermulst, G. E. Wijnands, and J. L. Duarte, "Isolated high-efficiency DC/DC converter for photovoltaic applications," in Proc. 38th Annual Conf. on IEEE IAS, 2012, pp. 25-28.

[8] I. H. Altas and A. M. Sharaf, "A Novel maximum power fuzzy logic controller for photovoltaic solar energy systems," Renewable Energy, vol. 33, no. 3, pp. 388-399, 2008

[9] C. Hua, J. Lin, and C. Shen, "Implementation of a DSP-Controlled photovoltaic system with peak power tracking," IEEE Trans Industrial Electronics, vol. 45, pp. 99-107, 1998.

[10] E. Koutroulis, K. Kalaitzakis, and V. Tzitzilonis, "Development of an FPGA-based system for real-time simulation," Microelectronics Journal, vol. 40, pp. 1094-1102, 2009.

[11] A. Mellit, H. Rezzouk, A. Messai, and B. Medjahed, "FPGA-based real time implementation of MPPT-controller for photovoltaic systems," Renewable Energy, vol. 36, pp. 1652-1661, 2011

[12] M. O. Badawy, A. S. Yilmaz, Y. Sozer, and I. Husein, "Parallel power processing topology for solar PV applications," IEEE Trans. Industry Applications, vol. 50, no. 2, pp. 1245-1255, 2014

[13] V. Salas et al., "Evaluation of a new maximum power point tracker (MPPT) applied to the photovoltaic stand alone systems," Solar Energy Materials and Solar Cells, vol. 87, pp. 807-815, 2005.

[14] T. Esram and P. L. Chapman, "Comparison of photovoltaic array maximum power point tracking techniques," IEEE Trans on Energy Conversion, vol. 22, no. 2, pp. 439-449, 2007.

[15] M. G. Wanzeller, R. N. C. Alves, and W. A. Santos, "Current control loop for tracking of maximum power point supplied for photovoltaic array," IEEE Trans. on Instrumentation and Measurement, vol. 53, pp 1304-1310, 2004.

[16] N. Onat, "Recent developments in maximum power point tracking technologies for photovoltaic systems," International Journal of Photo Energy, 2010.

[17] S. T. Kok and M. Saad, "Modified incremental conductance algorithm for photovoltaic system under partial shading conditions and load variation," IEEE Transactions on Industrial Electronics, vol. 61, no. 10, 2014.

[18] B. Burger and D. Kranzer, "Extreme high efficiency PV power converters," in Proc. 13th European Conference Power Electronics and Applications, September 2009, pp. 1-13.
[19] M. A. Özçelik and A. S. Yılmaz, "Effect of maximum power point tracking in photovoltaic systems and its improving and its application of wireless energy transmission," in Proc. 1st Journal Conference on Clean Energy and Technologies, Paris, France, 2014.

[20] A. E. Mohamed and Z. Zheng, "MPPT techniques for photovoltaic applications," Renewable and Sustainable Energy Reviews, pp. 793-813, 2013.

[21] F. Nicola, P. Giovanni, S. Giovanni, and V. Massimo, "Power electronics and control techniques for maximum energy harvesting in photovoltaic systems," Industrial Electronics Magazine, vol. 7, issue 3, pp. 71-74, 2013,

[22] M. A. Abdourraziq and M. Maaroufi, "A new variable step size INC MPPT method for PV systems," in Proc. IEEE Multimedia Computing and Systems (ICMCS) International Conference, 2014.

[23] I. Kashif and S. Zainal, "A review of maximum power point tracking techniques of PV system for uniform insolation and partial shading condition," Renewable and Sustainable Energy Reviews, pp. 475-488, 2013.

Mehmet Ali Özçelik was born in İskenderun, Turkey. He received the B.E., M.E., and $\mathrm{PhD}$ degrees in electrical education, Marmara University, Istanbul and in electrical \& electronics engineering, Sutcu Imam University, Kahramanmaras, Turkey, in 1999, 2006, 2015 respectively. He is currently an Asst. Prof. at the Department of Electric and Energy, Gaziantep University, Turkey. His field of interest includes PV energy conversion systems and MPPT algorithms.

Ahmet Serdar Yılmaz was born in Kahramanmaras, Turkey. He received the B.E., M.E., and Dr. Eng. degrees in electrical \& electronics engineering, Sakarya University, Turkey, 1994, 1997 and 2002, respectively. In 1995, he joined the Department of Electrical and Electronics Engineering, Sakarya University, as a research assistant then became an assistant professor and an associate professor in 2003 and 2011, respectively. He is a currently an associate professor at the Department of Electrical and Electronics Engineering, Sutcu İmam University, Kahramanmaras, Turkey. His current research interests include power quality, power systems, wind and solar energy conversion systems. He is member of the IEEE. 